\title{
ANÁlisis del CORPUS CRÍTICO TEATRAL PUBLICADO POR EL EDITOR GHIRALDO EN ObRaS INÉDITAS de GaLdós
}

\author{
EnRiQue Rubio CREMAdes \\ Universidad de Alicante
}

\section{RESUMEN:}

La prestigiosa editorial Renacimiento publicó en el año 1923 un total de doce volúmenes titulados Obras inéditas de Galdós. El correspondiente al volumen V, titulado Nuestro Teatro, el colector de dichas obras de Galdós, recopiló un corpus crítico referido a la crítica teatral y al mundo del teatro en general de gran interés para el conocimiento del ideario estético galdosiano y sus reflexiones sobre el estado de la escena española durante la segunda mitad del siglo XIX. El presente estudio aborda dichos aspectos basados en un conjunto de artículos que pueden considerarse una auténtica rareza bibliográfica.

\section{PALABRAS CLAVE:}

Galdós. Obras Inéditas. Teatro y crítica literaria.

\begin{abstract}
:
In 1923, the prestigious publisher Renacimiento published a total of twelve volumes titled Unpublished Works by Galdós. In Volume V, entitled Our Theater, the author of the collection compiled a critical corpus referred to theater criticism and the world of theater in general. This is of great interest for the knowledge of Galdosian aesthetic ideology and its reflections on the state of the Spanish scene during the second half of the 19th century. The present study addresses these aspects based on a set of articles that can be considered a true bibliographical rarity.
\end{abstract}

\section{KEYWORDS:}

Galdós. Unpublished Works. Theater and literary criticism.

En plena madurez literaria, publicadas sus Novelas españolas de la primera épo$c a$, las dos primeras series de los Episodios Nacionales y toda la producción de novelas conceptuadas por la crítica como naturalistas - configurada por la serie de Novelas Españolas Contemporáneas-, Ghiraldo publica una serie de trabajos sobre Galdós, fechados por él entre los años 1885 y 1890, como teórico de la literatura, de carácter crítico y ensayístico, reunidos y editados en 1923 con el título Obras inéditas. El marbete que engloba las reflexiones galdosianas sobre la dramaturgia española referidas en su mayoría al siglo XIX lleva el explícito título Nuestro Teatro, al igual que los volúmenes Fisonomías sociales, Arte y Crítica y Política Española. En la recopilación de trabajos llevada a cabo por Ghiraldo, un total de doce volúmenes 
(Política Española se publica en dos tomos), la cadencia editorial se extiende desde el año 1924 al 1928. Dicho corpus está configurado por los volúmenes Cronicón. 1883-1886 (1924); Cronicón. 1886-1890 (s.a.); Toledo. (Su historia y leyenda) (s.a.); Viajes y fantasías (1928), Memorias (1930); Crónica de Madrid (s.a.); y El crimen de la calle Fuencarral. En total doce volúmenes ordenados por Alberto Ghiraldo, colector y editor también de obras inéditas correspondientes a novelistas o poetas de ilustre tradición literaria, como sus volúmenes dedicados a Gertrudis Gómez de Avellaneda o a Rubén Darío. Cabe señalar que el monográfico Nuestro Teatro es confuso, pues no sigue el orden cronológico real, bien por desconocimiento de la fecha de publicación en que aparecen los artículos que configuran el volumen -de ahí que aparezcan algunos de ellos sin fecha alguna-, o por un cierto carácter aleatorio del colector que los configura en específicos bloques sin indicar el por qué. La datación de artículos que Ghiraldo ignora posibilita el desorden con el que se ofrecen al lector dicho volumen, de ahí que los hayamos fechado para un mejor conocimiento del proceso evolutivo de Galdós sobre su concepción del teatro.

El monográfico se inicia con un estudio referido a la historia de los teatros madrileños más representativos de todas las épocas. Dicho estudio, El teatro español, fechado en Madrid el 3 de diciembre de 1887, se refiere a los denominados Teatro Español, llamado en un principio Corral de la Pacheca o del Príncipe o el Teatro de la Cruz. Galdós se remonta a los orígenes fundacionales de dichos teatros, pues ofrece no solo noticias sobre las sociedades benéficas o cofradías que tuvieron el privilegio de explotación, sino también reflexiones sobre las corrientes estéticas y literarias desde los orígenes mismos del teatro hasta la época romántica e inicios del teatro de «alta comedia».

El artículo escrito por Galdós, fechado el 14 de febrero de 1885, es un enjundioso estudio sobre Echegaray, sobre los tics caracterizadores de su dramaturgia y modalidades de su obra teatral, desde la neorromántica o de tesis, hasta la simbolista o satírico-costumbrista. El estudio galdosiano lleva el elocuente título La escuela romántica y su pontífice, marbete harto significativo y que supone un cumplido elogio a su obra. Galdós señala al respecto que la pieza teatral titulada La peste de Otranto es el último drama publicado y estrenado en Madrid debido a Echegaray, equiparable a lo mejor de su producción dramática, como O locura o santidad, El Gran galeoto, La muerte en los labios y En el seno de la muerte. Conjunto de obras que para Galdós, hasta la fecha del 4 de febrero de 1885, es lo más aquilatado y señero de la producción teatral de Echegaray. Galdós destaca de la copiosa producción del dramaturgo cuatro piezas que a su juicio son de mayor calidad artística, pues se pueden acoplar a las tres modalidades literarias más representativas del dramaturgo. La primera, O locura o santidad, al teatro simbolista, que plantea graves problemas 
Análisis del corpus crítico teatral publicado por el editor Ghiraldo en Obras inéditas de Galdós

de conciencia; El Gran galeoto, al teatro de tesis, ya que intenta demostrar cómo el mundo con sus perversiones y reticencias puede actuar de engarce o medianero en una relación amorosa. El resto de su producción corresponde a la dramaturgia neorromántica, de cuyo corpus desdeña Galdós sus dos primeros dramas -El libro talonario y En el puño de la espada- con su silencio, pues solo se refiere a los dramas En el seno de la muerte y La muerte en los labios, ambas de gran inspiración, aunque tratados sus personajes de forma errónea y poco verosímil, fundamentalmente esta última, referida al suplicio de Servet en Ginebra a manos de los calvinistas. Evidentemente en el estudio galdosiano no figura la producción teatral satírico-dramática, iniciada, precisamente a finales del año 1884, con el drama Piensa mal y acertarás, que supone un cambio de dirección en el teatro de Echegaray. De hecho este cambio de gusto por parte del público se percibe a raíz del estreno de La peste de Otranto, pues a pesar de ser interesantísimo y lleno de efectos escénicos que deslumbran al espectador no produce gran entusiasmo entre el público, ya que «ni por el poder de la fantasía ni por la originalidad de las combinaciones teatrales aparece Echegaray en decadencia en esta obra. Consiste la frialdad relativa del público en ese indudable cambio de gusto que se va infiltrando con lentitud» (1923: 145).

Galdós es consciente de los cambios que se operan en la mente de los espectadores, de los habituales asistentes al teatro, que prefieren asuntos reales, que muestren la vida real, nuestra propia vida, con caracteres de sencillez y de verdad, sin prescindir de la intensidad de los afectos. Galdós afirma que Echegaray debería seguir por este nuevo rumbo, pues está perfectamente capacitado para llevarlo a cabo y en plenitud de facultades. De hecho, afirma Galdós, las grandes aptitudes de Echegaray «lucirían más aplicadas a un género en el cual los fulgores de la invención dan realce más vivo en las líneas severas y propias de la verdad» (1923: 145). Lo cierto es que a través de la reflexión de Galdós, Echegaray inicia un nuevo corpus cuyo enunciado, Costumbrista, encajaría bien con la pieza Piensa mal y acertarás, escrita a continuación de la reseñada por Galdós, La peste de Otranto. Obra teatral, Piensa mal y acertarás, de carácter costumbrista, satírico, con ligeros matices de carácter sicológico, al igual que las tituladas Un crítico incipiente, Sic vos non vobis o Mariana.

Galdós, estuvo siempre íntimamente ligado al teatro, aunque su presencia como dramaturgo no se llevó a cabo hasta las últimas décadas de su vida. Afición que se produce en plena juventud, tal como lo constatan sus piezas teatrales Quien mal hace bien no espere. Ensayo dramático en un acto y en verso original de un estudiante llamado Benito Pérez Galdós (1861), La expulsión de los moriscos. Drama (1864) y Un joven de provecho, publicada post-mortem por H. Chonon Berkowitz en 1935. Afición por el teatro que también se percibe en sus novelas tanto por su inclinación por el estudio de los valores humanos y la ausencia del paisaje, como por la presen- 
cia de lo dramático ligada a la suspensión del interés, declaraciones o revelaciones súbitas, finales o desenlaces teatrales. Sus Novelas españolas de la primera época, como Gloria o Marianela participan de este carácter teatral, dramático, como la muerte de Gloria y Daniel Morton, o Marianela, cuya muerte por desamor le aboca al suicidio, y a pesar de ser rescatada, fallecerá al poco tiempo. Amor, trabajo y libertad suponen los principales resortes de su teatro cuando Galdós ya se ha convertido en el gran novelista de la literatura y la creación o la adaptación dramática acaparan toda su atención, tal como se percibe en la siguiente relación de obras: Realidad (1892), La loca de la casa (1892), Gerona (1893), La de san Quintín (1894), Los condenados (1895), Voluntad (1896), Doña perfecta (1896), La fiera (1897), Electra (1901), Alma y vida (1902), Mariucha (1903), El abuelo (1904), Bárbara (1905), Amor y ciencia (1905), Pedro Munio (1908), Zaragoza (1908), Casandra (1910), Celia en los infiernos (1913), Alceste (1914), Sor Simona (1915), El tacaño Salomón (1916), Santa Juana de Castillo (1918) y Antón Caballero (1922). Toda una vida dedicada al teatro cuyos precedentes están marcados por las reflexiones tanto en el corpus titulado Decadencia como en el denominado por el propio Galdós Estrenos.

Tal como se ha señalado en un principio no todos los trabajos insertos por Ghiraldo en el volumen Nuestro Teatro aparecen fechados, como los capítulos denominados Un retrato, Estrenos, Decadencia, Otros géneros y El actor viajero. El primero de ellos revela un excelente pulso narrador por parte de Galdós, pues presenta al dramaturgo Hartzenbusch como si de un personaje novelesco se tratara, como:

[...] un hombre de pequeña estatura, delgado, erguido, de fisonomía animada, aunque grave; de color encendido, de mirada serena que se clava sucesiva y rápidamente en todos los objetos a través de los gruesos cristales de unos anteojos; de andar corto y precipitado. Este hombre, cuya edad frisa en los sesenta años [...] viste bien y lleva siempre un paraguas o la cabeza echada atrás, y mira a todos lados con desenvoltura y con gracia. Este hombre es el autor ilustre de Los amantes de Teruel, don Juan Eugenio Hartzenbusch (1923: 61-62).

Galdós hace un guiño al lector sobre la posible fecha de redacción del artículo al indicar que Hartzenbusch frisaba en los sesenta años. Teniendo en cuenta que nació el 6 de septiembre de 1806, la fecha posible de redacción podría datarse hacia los años 1865 o 1866, en la encrucijada de fechas que median entre sus colaboraciones en el periódico de La Palmas de Gran Canaria, El Omnibus, y su inicio en el periódico madrileño La Nación, con el marbete de progresista en la cabecera, fundado por Pascual Madoz. Lo extraño es que Ghiraldo no se planteara esta reflexión y lo incluyera sin fechas, al igual que otros artículos de Galdós que figuran en el volu- 
men. De haber sido así, el artículo sobre Hartzenbusch debería figurar al principio de la monografía, pues se publicó en La Nación el 4 de febrero de 1866, con el título Galería de hombres célebres. D. Juan Eugenio Hartzenbusch.

La disposición del corpus crítico llevada a cabo por Ghiraldo, a pesar de su buena intención, es caótica, confusa, pues estructura reflexiones sobre la dramaturgia emitidas en diversas etapas de su vida, sin llevar a cabo ninguna especificación pertinente. Otro tanto sucede con el estreno de obras teatrales juzgadas por Galdós en donde no figura fecha alguna, aunque sí pueden datarse con exactitud, como su ensayo sobre la comedia El abogado de pobres, de Bretón de los Herreros, publicado el 11 de febrero de 1866 en La Nación, o su artículo dedicado a la obra de Ventura de la Vega -La muerte de César-publicado también en dicho periódico el 11 de febrero de 1866. Otro tanto sucede con el epígrafe titulado Tumbas en el que no aparece fecha alguna, aunque, evidentemente, no entraña confusión, pues al tratarse de un artículo necrológico la datación es obvia, como en el caso del fallecimiento del célebre dramaturgo Ventura de la Vega. Galdós le dedica desde las páginas de La Nación un lúcido estudio sobre su persona y obra el 10 de diciembre de 1865. El orden de presentación, pues, llevado a cabo por Ghiraldo es harto aleatorio, de ahí que, si bien recopila un material noticioso de gran trascendencia, sea necesario ordenarlo para saber con exactitud el proceso evolutivo de Galdós sobre la escena, su visión de la escenografía, cambios de gustos estéticos y reacciones del público ante el estreno de determinadas obras.

En un extenso ensayo sin fechar, Viejos y nuevos moldes, Galdós analiza el comportamiento del público en materia de teatros, cansado de las viejas fórmulas dramáticas repetidas hasta la saciedad, de los convencionalismos reiterativos, de la actitud del público, de los empresarios y, en definitiva, de todo lo que atañe al teatro. Su visión del teatro en la primera mitad del siglo XIX, con especial detenimiento a la influencia de Scribe en la escena española, y su análisis del teatro denominado de alta comedia, encaja perfectamente con el bloque de encargos galdosianos que configuran el epígrafe Decadencia, configurado por el ya citado Viejos y nuevos moldes, Arte interpretativo (sin fecha), Espíritu de imitación (23 de noviembre de 1885) y El derrumbe ( 9 de febrero de 1886). El orden establecido por Ghiraldo está bien pergeñado pues permite captar con precisión los cambios que se operan al mediar el siglo XIX, ligados a nexos de índole político y social, percibiéndose también la actitud de un público que está más interesado por los problemas de su época, por la realidad circundante. Sin embargo, este teatro, dirigido en palabras de Galdós a un público burgués y casero está plagado de una insoslayable actitud moralizadora y a él, al público «se debe el predominio de esa moral escénica que informa las obras contemporáneas, una moral excesivamente destinada a aderezar la literatura dramá- 
tica, moral, enteramente artificiosa y circunstancial, como de una sociedad que vive de ficciones y convencionalismos» (1923: 155).

Para Galdós la restricción que esta moral impone al desarrollo de la idea dramática es causa de que los caracteres se hayan reducido sustancialmente, que su acción sea restringida y la variedad de asuntos repetidos hasta la saciedad. Moral impuesta por la burguesía que ha coaccionado a los dramaturgos, cercenando su talento y poder creador. Es evidente que este escrito, ofrecido por Ghiraldo sin datación alguna, está escrito en plena madurez, desde la atalaya que ofrece la experiencia de la vida, pues lleva a cabo un sutil y profundo análisis del corpus dramático del teatro de Alta comedia, sin citar, ni mencionar el nombre de ninguno de sus adalides, como Ventura de la Vega, López de Ayala, Tamayo y Baus, Roca de Togores, Rodríguez Rubí, Eguílaz, Serra, Sanz, Camprodón y otros de menor relevancia, como Coello, Nocedal o Suárez Bravo. Es obvio que Galdós conocía el pulso diario de la vida teatral madrileña. Su artículo es el reflejo de la conjunción y análisis de toda esta producción debida a los autores mencionados, cuyas obras están inmersas en parecidos contenidos: actitud moralizadora basada en casos sucedidos y en los que suele predominar una intención ideológica y moralizadora; personajes autoritarios que imponen los imperativos del deber a la pasión amorosa. Un teatro, en el decir de Galdós, que deambula sin rumbo, a capricho del público burgués, y cuyos asuntos se reducen «a tres o cuatro fábulas, la fábula del adulterio, la del desprecio de las riquezas, la de los novios que no pueden casarse porque los padres se odian y nada más [...] los caracteres han quedado reducidos al marido engañado, que siempre es el mismo, y ha venido a ser un verdadero muñeco de cartón, a la esposa infiel, el padre intransigente, al joven calavera, al amigo oficioso y entrometido. Estas riquezas obran y hablan con arreglo a una ley de humanidad puramente teatral. Las acciones responden a una moral que solo existe de telón adentro» (1923: 155-156).

Es indudable que para Galdós todo lo que sucede en la escena constituye un mundo aparte, que no es real, y, sin embargo, o a pesar de ello, el público lo da por bueno y aplaude sus obras. Un público que con el correr de los años muestra un hastío por lo repetitivo de sus asuntos, que demanda otras acciones y afectos, que los caracteres y la reproducción de la vida configuren el fondo de la composición. Sin embargo, el público no percibe o no se da cuenta de lo mismo que desea, pues desdeña y se aburre de lo común y corriente, recibiendo con no poca prevención todo lo que rompa la rutina de las combinaciones escénicas, pues un concepto o una situación original, novedosa, dejan al público frío. La sociedad en general y el llamado gran público «no vibran sino con ideas y sentimientos de fácil adquisición, con todo aquello que se saben de memoria, y se tiene ya por cosa juzgada y consagrada» (1923: 159). 
Análisis del corpus crítico teatral publicado por el editor Ghiraldo en Obras inéditas de Galdós

Si en su ensayo Viejos y nuevos moldes brilla por su ausencia el mundo de los actores, en el titulado Arte interpretativo Galdós analiza el arte de la declamación con detalle y precisión, mostrando sus defectos y las peculiaridades del mismo. Ensayo que puede completarse con el estudio que da fin al volumen Nuestro Teatro: El actor viajero: Vico. En Arte interpretativo Galdós se asemeja en múltiples ocasiones a los juicios emitidos por Larra en sus artículos de crítica teatral, consciente de la importancia de los actores en el fracaso o éxito de una pieza dramática. Galdós se muestra un tanto descorazonado con los responsables de llevar a buen puerto una obra teatral, pues en su opinión no existe el paralelismo perfecto entre la belleza abstracta de una comedia o un drama y la belleza concreta de una representación. Tanto el actor como la actriz deben representar su papel en consonancia con lo dictado por el creador de la obra, pues es necesario atenerse con total fidelidad al texto, interpretar fielmente la obra que se le encomienda. Sin embargo, el intérprete prefiere el aplauso, aspira al éxito antes que la fidelidad de la obra, de ahí el amaneramiento de los actores que reina en los teatros.

Si bien es verdad que Galdós censura dicha actitud, entiende que en determinadas ocasiones los cómicos de más talla, como los Romeas, Valeras y Arjonas, consiguen el éxito de las obras gracias a su amanerado arte y donaire, pero aun así se muestra escéptico, contrariado, porque se cercena la originalidad del texto creado por el dramaturgo. Lo cierto es que las obras desde tiempo inmemorial se escriben en función del actor o de la actriz, tanto en el teatro español como en el resto de Europa. Los críticos, según Galdós, recomiendan que se escriban las obras sin pensar en los actores. Esto, aunque puede parecer justo y desde un punto de vista teórico no se puede contradecir, en la práctica, según Galdós, resulta un disparate, pues en su opinión «las obras capitales del arte dramático han sido escritas para determinados histriones. Molière y Shakespeare sabían, desde que ideaban un drama o comedia, quien lo había de interpretar» (1923: 170).

Galdós ofrece en la monografía Nuestro Teatro un material noticioso de gran valor para entender los entresijos de la escena española del último tercio del siglo XIX. No solo teoriza sobre las cualidades que toda obra debe reunir para ser respetada por la crítica y el público, sino que también analiza determinados comportamientos del público propiciados por empresarios y actores que son determinantes para el éxito de una representación. Nos referimos a la claque, interpretación que podrá ser todo lo ridícula que se quiera, «pero el estado actual del Teatro, la hace indispensable» (1923: 174). Para Galdós el cuerpo de alabarderos no tiene otra misión que difundir en el recinto teatral esa emoción o calor que predispone al público a su sensibilidad y aguza su entendimiento para entender e interpretar mejor lo que ve y oye. Desempe- 
ñada su misión con prudencia, sirve para animar y tener despierto el interés del público.

Según Galdós la década de los años ochenta es deplorable para el teatro. La abundancia de adaptaciones, traducciones y arreglos de obras son un claro exponente de la falta de obras originales. La calidad de los textos es nula. Abundan los caracteres falsos y exagerados, los diálogos y versificación carecen de valor. Todo ello revela, en el sentir de Galdós, la falta de estudio y el desconocimiento de todo lo que rodea al arte escénico. La decadencia del teatro español es evidente en la España de finales del XIX, acrecentada por la invención de algunos géneros literarios de dudosa naturaleza que servían para amenizar el árido estilo de los carteles anunciadores, como disparates cómicos, pasillos cómicos, quidproquos en un acto, oportunidades en dos y sainetes en tres. La decadencia del teatro se deja sentir también de forma profunda en la zarzuela, pues la excelente calidad de los músicos de antaño brilla por su ausencia. El desvalido arte nacional, riquísimo en sus elementos y apto en gran manera para la creación de bellísimas y excelentes obras, es inexistente. En febrero de 1886 Galdós en su artículo El Derrumbe se muestra asaz asolado, triste, en idéntica actitud a la de Fígaro, pues los traductores, cual lacra que invade la escena teatral española, se han erigido en los mantenedores de los teatros. El texto con el que da comienzo a su artículo Galdós es harto elocuente:

Lloremos hoy sobre los despojos del teatro más brillante de las literaturas modernas; lloremos sobre las cenizas ilustres, en las cuales están escritos tantos preclaros nombres, desde los de Lope y Calderón hasta los de Ayala y Hartzenbusch. Porque nuestro glorioso teatro no existe ya. Todo desapareció; no queda nada (1923: 191).

En Nuestro Teatro aparece también un corpus referido a la música, a la ópera, fundamentalmente. Páginas de carácter informativo y que no se pueden comparar con el copiosísimo material noticioso que figura en el periódico La Nación, en cuyas páginas dio Galdós probadas muestras de su conocimiento e interés por la música. Otro tanto sucede con el denominado Arte por horas, descrito de forma concisa por Galdós en su monografía, al igual que el estudio de determinados actores famosos de la época, como el titulado Vico, amigo personal de Galdós, excelente actor y citado por el novelista en un episodio nacional Cánovas. Nuestro Teatro muestra, en definitiva, el interés que Galdós tuvo siempre por el teatro, desde el inicio de su singladura como escritor hasta sus últimos años. Una afición que vertebra toda su producción literaria y que se deja sentir en no pocos momentos de producción novelística. 
Análisis del corpus crítico teatral publicado por el editor Ghiraldo en Obras inéditas de Galdós

\section{Bibliografía}

Berkowitz, H. Chonon. «Un joven de provecho, an unpublished play by Pérez Galdós», Publications of the Modern Language Association of America, L, $\mathrm{n}^{\circ}$ 3,1935, págs. 833-896, 1 facsímil.

Echegaray, José, La peste de Otranto, Madrid, Imprenta de José Rodríguez, 1884. Pérez Galdós, Benito, Nuestro Teatro. Obra inédita de Benito Pérez Galdós (editor Ghiraldo), Madrid, Editorial Renacimiento, 1923.

Sancha Fernández, El Teatro de las Comedias de Madrid (1875-1915): su historia y reconstrucción de la Cartelera, Madrid, UNED. Tesis doctoral, 2015. 